\title{
LÁZARO: REALISMO E IRONIA EM JOÃO 11:1-55
}

Cristhiano Aguiar*

(iD) https://orcid.org/0000-0003-4334-691X

João Leonel **

(iD) https://orcid.org/0000-0003-3600-3695

Como citar este artigo: AGUIAR, C.; LEONEL, J. Lázaro: realismo e ironia em João 11:1-55. Todas as Letras - Revista de Lingua e Literatura, São Paulo, v. 23, n. 3, p. 1-12, set./dez. 2021. DOI 10.5935/1980-6914/eLETDO2114932

Submissão: novembro de 2021. Aceite: novembro de 2021.

Resumo: Nosso artigo se propõe a fazer uma análise literária de um importante episódio do Evangelho de João: o da ressurreição de Lázaro, narrado exclusivamente no evangelho citado no capítulo 11, versículos de 1-55. Nossa leitura procurará se ater a alguns elementos: 1 . cenas-padrão e paralelismos; 2. a construção de momentos de suspense e tensão narrativos; 3. a caracterização das personagens, com ênfase na construção da figura de Jesus no episódio; 4. o manejo de códigos e procedimentos vinculados às noções de "realismo" e "ironia". Nossa análise tomará por base a tradução do evangelho de João feita por Frederico Lourenço (2017). Como fundamentação teórica, nossa pesquisa se ampara em A arte da narrativa bíblica (ALTER, 2007), New testament history and literature (MARTIN, 2012), Mimesis (AUERBACH, 2021), Abaixo as verdades sagradas (BLOOM, 2012) e Ironia e suas refrações (ALAVARCE, 2009).

Palavras-chave: Evangelho de João. Ironia. Realismo. Bíblia. Crítica literária. 


\section{INTRODUÇÃO}

$\mathbf{P}$

ropomos analisar um dos mais significativos episódios dos evangelhos, a ressurreição de Lázaro, sob o olhar da critica literária. Nossa abordagem buscará compreender o episódio como uma narrativa que possui autonomia literária. Ou seja: analisaremos a construção do texto do evangelho de João, dando especial atenção às suas estratégias narrativas.

Dois conceitos são importantes em nossa análise: realismo e ironia. Uma visão apressada pode considerá-los estranhos ao nosso objeto. Para um leitor não religioso, ou até cheio de pré-julgamentos em relação ao Novo Testamento, a ideia de "realismo" na base do relato de um dos mais importantes milagres de Jesus pode causar estranheza. Por outro lado, um leitor religioso pode sentir estranheza semelhante, como se a noção de "realismo" de alguma maneira buscasse anular a dimensão teológica da narrativa de João.

Ironia é também uma ideia que, à primeira vista, pode ser considerada de problemática associação às Sagradas Escrituras. Traço considerado fundamental da modernidade e das literaturas modernas, a ironia tem sido tema de intensas investigações por parte das teorias literárias e linguísticas contemporâneas. Do Romantismo às narrativas contemporâneas, a ironia caracteriza-se como uma importante chave de compreensão teórica no âmbito dos estudos literários. Assim, não seria um exercício anacrônico associar um texto como o Evangelho de João ao conceito de ironia?

No campo das relações entre Bíblia e Literatura, importantes referências bibliográficas indicam, por outro lado, o quanto pensar "realismo" e "ironia" não só é adequado ao entendimento da Bíblia, como, na verdade, os dois conceitos nos ajudam a entender mecanismos fundamentais daquilo que nos fascina nos textos bíblicos. Em obra-chave não somente para os estudos da Bíblia como literatura, mas também para a crítica literária no século XX, Erich Auerbach (2021), em seu Mimesis, dedica dois capítulos à questão do realismo na Bíblia. Já Robert Alter (2007) e Harold Bloom, que produziram reflexões fundamentais para a relação entre Bíblia e Literatura, destacam não somente a problemática do realismo na Bíblia (e as relações da Bíblia com os discursos que hoje chamamos de História), mas igualmente a questão da ironia. Em diversos ensaios, Bloom, por exemplo, aponta uma das fontes narrativas do Gênesis, o Javista, como um dos grandes ironistas da literatura em todos os tempos: "Do modo como o leio, J é o mais irônico dos escritores, com uma ironia singular, que resulta sempre dos embates não resolvidos de realidades totalmente incomensuráveis" (BLOOM, 2012, p. 21).

Inspirados, portanto, nos trabalhos pioneiros de Auerbach, Alter e Bloom, tentaremos responder à seguinte questão: de que modo realismo e ironia operam na construção das estratégias narrativas de João 11:1-55?

\section{REALISMO E IRONIA: ALGUMAS DEFINIÇÕES}

A questão do "realismo" parte daquilo que Auerbach estabelece em sua obra Mimesis. Ao longo do livro, o crítico literário alemão se indaga a respeito das formas pelas quais a literatura, com foco na literatura ocidental, buscou representar a realidade cotidiana. Auerbach percebe que desde a poesia homérica existe 
uma tendência de o cotidiano e as classes sociais não aristocráticas serem representados em pelo menos um de dois registros: o cômico ou o idílico (AUERBACH, 2021, p. 24). Por conseguinte, as questões sublimes, trágicas, sérias e elevadas tendem a evitar a representação da vida cotidiana, focando, também, em personagens míticos e/ou pertencentes aos estratos aristocráticos das sociedades que produzem suas respectivas literaturas. A mistura dos estilos - criar uma peça trágica com personagens burgueses, por exemplo - está, segundo Auerbach, na origem do realismo moderno, cujo desenvolvimento se acentua, no Ocidente, em especial a partir do século XVIII.

Segundo Auerbach, boa parte da literatura na Antiguidade pratica, em maior ou menor grau, a separação dos estilos. Uma notável exceção, porém, é a Bíblia: "A sublime intervenção de Deus age tão profundamente sobre o cotidiano que os dois campos do sublime e do cotidiano são não apenas efetivamente inseparados, mas, fundamentalmente, inseparáveis" (AUERBACH, 2021, p. 24). Tanto no Antigo Testamento quanto no Novo Testamento, são narrados episódios que tratam com seriedade a vida cotidiana e suas personagens de extração não aristocrática. Se ficarmos somente com o Novo Testamento, é digno de nota o quanto o protagonista dos evangelhos, Jesus Cristo, o Messias e Deus tornado carne, tem uma origem bastante humilde, sendo filho de um carpinteiro. Conceder ao salvador da humanidade origem tão humilde - não obstante haja na genealogia de Cristo uma origem davídica - é algo que seria estranho, por exemplo, ao mundo de Homero ou de Eurípides. Ao comentar outro importante personagem dos evangelhos, o apóstolo Pedro, o autor de Mimesis conclui:

Pedro não é mera figura acessória que serve apenas de illustratio, como os soldados Vibuleno e Percênio, apresentados como simples patifes e tratantes, mas é, no mais elevado, profundo e trágico dos sentidos, uma imagem do homem (AUERBACH, 2021, p. 45).

Debater o realismo na Bíblia, portanto, é essencial para entendermos o que diferencia o Antigo Testamento e o Novo Testamento de boa parte da literatura clássica, seja esta escrita em grego ou latim. É no debate, ainda, sobre a construção de efeitos realistas de sentido que repousa a espinhosa questão da historicidade da Bíblia, debate este, porém, que não é o objetivo do presente artigo.

Em relação à ironia, como conceituá-la?

Para Camila da Silva Alavarce (2009, p. 28-29), em seu livro A ironia e suas refrações: um estudo sobre a dissonância na paródia e no riso, a ironia é conceituada nos seguintes termos:

O contraste entre a aparência e a realidade é o traço básico de toda ironia. Conforme se observou nos exemplos irônicos citados anteriormente, algo é aparentemente afirmado, mas, na verdade, se percebe uma mensagem completamente diferente. A tensão entre aparência e realidade pode expressar-se por meio de uma oposição, contradição, contrariedade, incongruência ou, ainda, através de uma incompatibilidade. [...] Fica fácil perceber, dessa maneira, que o estudo da ironia exige o reconhecimento de um sentido literal e de outro figurado, uma vez que esse "recurso" se constitui de um significante para dois significados contraditórios ou incompativeis. Aquele que pratica a ironia qualifica o enunciatário, pois o julga capaz de perceber os indices que sinalizam esse procedimento, participando, assim, da construção da significação irônica. 
Alavarce desdobra a ideia de ironia a partir da apresentação das perspectivas teóricas de D. C. Muecke. Segundo esse autor, há dois tipos de ironia: a ironia situacional ou observável e a ironia verbal ou instrumental (ALAVARCE, 2009, p. 25). A ironia verbal é aquela que se expressa de maneira propriamente linguística, por meio da frase de efeito, do chiste, da "tirada" sagaz. A situacional, por outro lado, consiste em uma cena, da vida cotidiana ou das narrativas, à qual pode ser atribuída uma leitura irônica. Nas duas categorias, no entanto, temos sempre a incongruência, o contraste entre a aparência e o sentido oculto, a tensão entre aquilo que é exposto e uma referência oposta a ser decodificada da situação ou da construção linguística. Outra dimensão da ironia é a de Umberto Eco. Em seu ensaio "Ironia intertextual e níveis de leitura", o escritor italiano desenvolve o conceito de "ironia intertextual", que consiste em uma camada não explícita de citação textual, a ser percebida pelo leitor, em uma obra literária (ECO, 2011).

\section{JOÃo 11:1-55: REALISMO E CONSTRUÇÃO NARRATIVA}

O Novo Testamento possui quatro evangelhos. Três deles - Mateus, Marcos e Lucas - trazem elementos em comum: estrutura geográfica focada na Galileia, região norte da Palestina onde Jesus desenvolve suas atividades, e Jerusalém, para onde se dirige nos últimos dias, sendo preso, julgado, morto e ressuscitado. No início, após o surgimento de João Batista, seguem-se o batismo e a tentação de Jesus; a pregação do reino de Deus ou dos céus por Jesus; a realização de milagres etc. Em razão disso, os três são chamados de "evangelhos sinóticos", isto é, que podem ser lidos conjuntamente.

O evangelho de João é diferente dos demais. Logo no início, Jesus se dirige a Jerusalém. Sua tentação não é registrada. O tema do reino de Deus está praticamente ausente. Os milagres são identificados como "sinais". Para além disso, pode-se dizer que a narratividade do quarto evangelho distancia-se da dos demais. Frank Kermode (1997, p. 486) destaca esse aspecto:

$O$ engenho narrativo de João tem as virtudes da economia, complexidade $e$ profundidade. Ele está empenhado em tornar sua narrativa coerente, mas, ao fazê-lo, sempre trata de seu propósito mais profundo, que é a representação do eterno em relação ao transitório, das manifestações do ser em um mundo de vir-a-ser. Em outras palavras: embora haja uma quantidade excepcional de fala em João - seu Jesus, em discurso e diálogo, é de longe o mais comunicativo dos quatro -, ele tem ainda em grau maior do que os outros preocupação com a organização temática da narrativa, a criação de detalhe à maneira da história e o que é às vezes chamado de "efeito de real".

Segundo Dale B. Martin, no livro New Testament: history \& literature (2012), o evangelho de João tem alguns temas recorrentes, entre os quais os contrastes entre ascensão e queda, luz e escuridão, enxergar e conhecer (MARTIN, 2012, p. 152). A narrativa de Lázaro aproxima-se desses temas apontados por Martin, como veremos. Trata-se de um dos episódios mais famosos do Novo Testamento, embora, para a nossa surpresa, João seja o único a relatá-lo dentre os quatro evangelhos canônicos.

O que é narrado em João 11:1-55? O milagre da ressurreição de um morto chamado Lázaro. A partir das informações de João, podemos supor que Lázaro 
fazia parte de um ciclo mais íntimo de Jesus Cristo, pois o evangelista nos informa que Jesus o amava. Ao receber a notícia da morte de Lázaro, Jesus prepara a sua ida à aldeia de Betânia, onde o falecido morava. A situação, contudo, é envolta em tensão, pois há um clima de ameaça, oriundo da perseguição por parte das autoridades judaicas locais, envolvendo o ministério de Cristo.

Ao chegar em Betânia, Jesus interage com a família de Lázaro, bem como com a população do local. Em seguida, diante do túmulo do amigo, Jesus ordena que ele saia dali, no que é atendido pelo morto, que de imediato ressuscita. A narrativa finaliza com um epílogo, no qual o evangelista cria uma cena em que autoridades judaicas tramam a morte de Cristo.

Em termos da construção narrativa do evangelho de João, qual a importância da história de Lázaro? Resposta: ela é um elo essencial, pois se revela como o ápice dos sinais e milagres do ministério de Jesus Cristo na terra. Lázaro é, dessa maneira, o episódio-clímax a indicar uma das mais importantes mensagens desse evangelho: Jesus é de fato o Messias. O crescendo dos milagres e sinais caminha em paralelo com outra dimensão, a da tensão narrativa. No episódio, a reação preocupada dos discípulos de Jesus demonstra o quanto a prisão e possivel execução do mestres eram uma realidade cada vez mais próxima. João 11:1-55 materializa tanto o ápice da revelação messiânica quanto o ápice do perigo que circunda a figura de Jesus e dos seus discípulos. Não é exagero afirmar, portanto, que João 11 é o capitulo-convergência dessas duas linhas narrativas de João.

O episódio não pode ser totalmente avaliado à luz das estratégias narrativas modernas e contemporâneas. Fosse um conto, ou um capítulo de um romance, seria inverossímil Lázaro, figura do círculo íntimo de Jesus, aparecer só no fim da história. A sua morte, segundo padrões narrativos modernos, precisaria ser ao menos explicada de alguma maneira. Foi um súbito ataque cardíaco? Lázaro já vinha doente? O evangelho nada explica. A lógica narrativa da Bíblia, porém, é outra, como bem apontam, em diferentes escritos, Auerbach, Bloom e Alter.

Auerbach (2021, p. 11), por exemplo, sintetiza muito bem essa importante e peculiar característica literária da Bíblia: "Do outro lado, só é acabado formalmente aquilo que nos fenômenos interessa à meta da ação; o restante fica na escuridão". Lázaro surge na história somente quando ele é absolutamente necessário para o desenvolvimento da mensagem fundamental, a da afirmação, a do desvelamento, da verdadeira natureza de Jesus como o Messias. Tal lógica narrativa, bastante estranha aos nossos valores literários atuais, foi durante muito tempo avaliada como algo negativo, o que levou inúmeros leitores e críticos literários a considerar a Bíblia "mal escrita".

Por outro lado, o posicionamento do episódio de Lázaro num ponto culminante da narrativa de João é um traço que dialoga bem com parâmetros atuais de construção e valoração narrativas. Estar no capítulo 11 de João, diante de tudo que foi relatado pelo evangelista anteriormente, estabelece um nexo de causalidade bastante verossímil não só em relação ao que ocorre dentro do capítulo a hesitação dos apóstolos, diante da ameaça iminente de prisão, em irem até Betânia, por exemplo -, como com os desdobramentos posteriores ao milagre. É como se Lázaro fosse a "gota d'água" na visão das autoridades judaicas: é devido à ampla repercussão do milagre da ressurreição do morto que essas mesmas autoridades decidem prender e condenar Jesus à morte.

Passemos, agora, à primeira dimensão mais específica da nossa análise: há realismo em João, ao menos nos termos pensados por Auerbach? A resposta é 
sim. O evangelho de João mantém a tendência da representação séria da vida cotidiana e das personagens das classes sociais humildes, característica recorrente por toda a Bíblia, tanto no Antigo quanto no Novo Testamento. Vale a pena destacar, além disso, que o episódio, embora marcado pelo realismo cotidiano, inspira-se naquilo que Alter chama de "cena-padrão", ou seja, um conjunto de acontecimentos predeterminado que poderiam ser seguidos pelos autores na representação de determinadas cenas. Esta lógica de composição não é exclusiva da Bíblia, sendo identificável em inúmeras obras literárias da Antiguidade, como também em períodos literários posteriores. Tal lógica, em suma, aponta para uma dimensão mais convencional (utilizamos a palavra sem sentido pejorativo) e tradicional da composição literária. A modernidade literária se desenvolve, em especial a partir do Romantismo, justamente a fim de questionar tanto as poéticas da emulação dos modelos literários legitimados quanto a obrigatoriedade da continuidade de convenções poéticas materializadas, por exemplo, nas cenas-padrão.

Como o conceito de cenas-padrão se relaciona com João? Primeiro, cabe propor a seguinte divisão de João 11 :

1. 11:1-16: proposição do conflito da narrativa. Jesus conversa com os discípulos. Viagem até Betânia;

2. 11:17-37: a visita de Jesus;

3. 11:38-46: o milagre da ressurreição de Lázaro;

4. 11:47-55: epílogo da narrativa. As autoridades judaicas conspiram para assassinar Jesus.

Logo, uma parte do episódio de Lázaro é uma variação da cena-padrão da "visita", definida nos termos abaixo por Alter (2007, p. 84):

A cena-padrão da visita, por exemplo, deve se desenrolar de acordo com o seguinte padrão fixo: um visitante se aproxima; alguém o reconhece, levanta-se e vai cumprimentá-lo; o visitante é tomado pela mão, guiado até a sala, convidado a sentar-se na cadeira de honra; o visitante é convidado a participar do banquete; segue-se uma descrição do cardápio. Em Homero, quase todas as descrições de uma visita reproduzem aproximadamente essa sequência, não por uma sobreposição de fontes, mas porque a convenção exige que assim seja.

A cena-padrão da "visita" ecoa principalmente nas partes 2 e 3 da narrativa. Jesus, ao chegar perto de Betânia, não se aproxima imediatamente da cidade, ficando nos seus arredores. Ele é saudado por alguém que sai da própria casa a fim de encontrá-lo. A primeira pessoa a fazer isso é Marta; em seguida, Maria. Desse ponto em diante, a cena-padrão não é seguida à risca, porém propomos a hipótese de que as recorrências-padrão seguintes podem ter inspirado o evangelista a dar forma ao que acontece logo depois. Porque a importância de Jesus como visitante ilustre é a todo o momento afirmada pela fala desesperada das personagens - Maria, Marta e os demais judeus que acompanham tudo reiteram a crença de que Jesus teria curado Lázaro, se tivesse chegado antes: "Senhor, se aqui tivestes estado, o meu irmão não teria morrido" (João 11:32); "Não podia este, que abriu os olhos do cego, ter feito com que ele não morresse?" (João 11:37).

Além disso, Jesus é conduzido à tumba de Lázaro: não há aqui uma forma de comunhão, um eco da Santa Ceia antes de Cristo ser preso pelas autoridades? 
Cristo vai à tumba de Lázaro para conceder a vida; tal gesto é o oposto da Ceia feita como um preparatório ao martírio. Podemos supor, por fim, que após a ressurreição de Lázaro uma grande festividade, com comida e bebida, é feita em comemoração ao retorno do personagem do mundo dos mortos.

Voltemos, contudo, às considerações mais específicas a respeito do realismo. Se olharmos com atenção o tempo e o espaço de João 11, veremos que a sua abordagem converge com as interpretações da nossa fundamentação teórica. Não se trata de "bater o martelo" sobre se a geografia de João é 100\% precisa, ao menos nos termos como entendemos a geografia hoje, mas de entender que o texto busca transmitir uma espacialidade narrativa verossímil, não alegórica, calcada em uma vivência das distâncias e dos marcos temporais enraizada na experiência cotidiana dos seus leitores originais. A comoção, os rituais fúnebres, os tempos de deslocamentos, nada disso nos lança a um tempo mítico ou a-histórico. Muito pelo contrário.

Tratamento semelhante é conferido à complexidade psicológica das personagens. A grande surpresa, aqui, é o protagonista da narrativa: Jesus de Nazaré. Poucas vezes, nos quatro evangelhos, será possivel presenciar a montanha-russa de emoções a envolver esse personagem. Oscilando entre a divindade e a humanidade, é digno de nota que a faceta humana, emotiva, de Jesus, se revele ao mesmo tempo que acontece o seu maior milagre. Um muito humano Jesus ressuscita um homem há quatro dias morto: a afirmação da sua divindade ocorre dentro de um turbilhão de emoções humanas vividas por ele e por todos os que o cercam.

Vejamos o seguinte trecho:

Guando Marta ouviu que Jesus vinha a caminho, foi ao encontro dele. Maria ficou sentada em casa. Marta disse a Jesus: "Senhor, se aqui tivesses estado, o meu irmão não teria morrido. Mas agora eu sei que tudo o que a Deus pedires, Deus to dará". Jesus dize-lhe: "O teu irmão ressuscitará". Diz-lhe Marta: "Sei que ressuscitará na ressurreição, no dia derradeiro". Disse-lhe Jesus: "Eu sou a ressurreição e a vida [...]". Quando Maria chegou aonde estava Jesus, ao vê-lo atirou-se aos seus pés, dizendo-lhe: "Senhor, se aqui tivesses estado, o meu irmão não teria morrido!”. Jesus, quando a viu chorando e viu chorando os judeus que tinham vindo com ela, irritou-se no espírito e agitou-se. E disse: "Onde é que o depusestes?". Dizem-lhe: "Senhor, anda e vê". Jesus chorou (João 11:20-35, grifo nosso)

Há nuances emocionais às quais devemos prestar atenção.

Marta e Maria, as duas irmãs de Lázaro, lidam com o luto de maneiras diferentes. O narrador não explica tais diferenças. Pelo contrário, com concisão, o narrador expõe as diferenças na maneira como as duas mulheres agem em cena e por meio do modo como falam. Marta tem um maior controle das suas emoções, ao contrário de Maria, que, desolada, não consegue sair de casa. Marta, ao encontrar Jesus, faz de imediato uma cobrança: se você estivesse entre nós, nada disso teria acontecido. Há submissão e ressentimento em sua atitude. Jesus, por outro lado, prega a ela e lhe exige um ato de fé, prontamente obedecido pela sua interlocutora.

A cena do encontro de Jesus com uma mulher se repete. O narrador troca Marta por Maria, que diz exatamente a mesma frase que sua irmã. O paralelismo nos remete às típicas repetições dos contos maravilhosos. Porém, a repetição 
revela um jogo habilidoso do evangelista. Porque, ao contrário da irmã, Maria se joga aos pés de Cristo. Sua fala é igual à da irmã, mas muito mais carregada de emoção, cobrança e ressentimento: se você estivesse entre nós, nada disso teria acontecido! A ação e a pontuação fazem toda a diferença.

Jesus não reage como uma divindade toda poderosa, impassivel. Ele se irrita e se agita com o comportamento de Maria e com o choro dos "judeus que tinham vindo com ela". Ao saber o local do enterro, uma gruta, Jesus desaba e chora. A cena impressiona. Ela se ancora em um realismo psicológico, na verossimilhança da montanha-russa emocional pela qual passam personagens em uma situação-limite. Por que Jesus se irrita, por que ele chora? Ele está sob pressão de uma ameaça de morte. Sabe que ressuscitar Lázaro significa assinar a sentença da sua própria execução.

Como se não bastasse, ele está emocionalmente vinculado ao trio: "Jesus amava Maria, a irmã dela e Lázaro" (João 11:5). O seu choro vem da compreensão da finitude humana. A sua irritação, por outro lado, pode vir do ceticismo de Maria e "dos judeus", das suas acusações. Ora, ele já explicara a Marta que era preciso dar um salto de fé e acreditar, literal ou metaforicamente, na vida dentro da morte. Jesus talvez supusesse que Marta tivesse transmitido a Maria sua mensagem - "Eu sou a ressurreição e a vida [...]" (João 11:20) - e, por isso, esperasse uma atitude menos desesperada por parte de Maria.

Todo o trabalho de psicologia das personagens, cujo ápice emocional está entre os versículos 20-35, constrói o realismo do capítulo 11. Esse realismo está igualmente nos detalhes que descrevem o ressuscitado saindo da sua tumba: "O morto saiu com os pés e as mãos ligados de panos e com o rosto ligado com um sudário. Diz-lhes Jesus: 'Desligai-o e deixai-o andar'” (João 11:44). Ou seja: não há dúvidas de que um cadáver ressuscitou. A informação, aliás, de que "Tendo chegado, Jesus encontrou Lázaro já há quatro dias no túmulo" João 11:17) não é gratuita: serve para reafirmar o espetáculo da ressurreição, complementado pela descrição dos panos, do sudário e da impactante frase de Marta: "Senhor, ele já fede; pois é já o quarto dia” (João 11:39).

\section{JOÃO 11:1-55: IRONIAS SITUACIONAL, VERBAL, INTRATEXTUAL E INTERTEXTUAL}

O episódio de Lázaro é marcado pelo uso intenso da ironia.

Nesse sentido, o episódio não é um caso isolado no evangelho de João, ou nos demais evangelhos de Marcos, Mateus e Lucas. Pelo contrário, as falas de Cristo, bem como diversas cenas nas quais ele é um dos protagonistas, estão marcadas por duplos sentidos, por aquela incongruência de significados que, como vimos, é uma das marcas da ironia. Fica em aberto a questão do possivel efeito humorístico da utilização da ironia por parte dos evangelistas. É provável que nunca tenhamos efetiva certeza do quanto uma leitura pública de um episódio como Lázaro, por exemplo, poderia causar, em seu público original, alguma reação vinculada ao riso. A noção de ironia, contudo, extrapola o efeito imediato do riso. Mesmo que não achemos o episódio de Lázaro "engraçado" - pelo contrário, ele é, como vimos, formado por drama e catarse -, isso não implica uma anulação da dimensão irônica do texto.

Um ponto de destaque, em relação ao debate que propomos, é o quanto existe uma rica variedade de usos da ironia em João 11. Isso nos chama a atenção 
devido ao fato de que se trata de um texto curto e escrito em uma linguagem marcada pela concisão. Não obstante, a pluralidade irônica se revela em nossa leitura. A ironia como engenho linguístico - ironia verbal - é a primeira faceta a ser destacada. Dois dos seus momentos mais significativos acontecem nas cenas preparatórias para a viagem que Jesus e seus discípulos farão até a cidade onde Lázaro morava:

Disse essas coisas e, de seguida, diz-lhes: "Lázaro, o nosso amigo, adormeceu. Mas vou para o despertar do sono". Os discipulos disseram-lhe: "Senhor, se ele adormeceu, se salvará”. É que Jesus falara da morte de Lázaro, mas eles pensaram que ele está falando do descanso do sono. Foi então que Jesus lhes disse claramente: "Lázaro morreu" e alegro-me por vossa causa, para que creiais, por eu não ter estado lá. Mas vamos até ele. Disse então Tomé, o chamado Gêmeo, aos condiscípulos: "Vamos também nós para que morramos com ele” (João 11:11-16, grifo nosso).

"Nosso amigo" - outra vez, nos deparamos com uma lógica narrativa diferente daquela à qual nos acostumaram os valores literários da modernidade literária. Como foi salientado, uma construção narrativa, como a entendemos hoje, teria estabelecido, antes da sua morte e ressurreição, um relacionamento prévio mínimo entre Lázaro, Jesus e os discípulos. O evangelho de João não o faz. Como leitores, precisamos fazer um esforço extra de imaginação e completar os sentidos omitidos pelo narrador. Dessa maneira, podemos supor que a informação da doença grave de Lázaro é um choque para os discípulos de Cristo, que no minimo o conheciam com alguma intimidade.

Tendo tal fato em mente, conseguimos dar um peso a mais ao verbo "adormecer". Imaginemos, na cena, o alivio dos discipulos ao ouvir de uma figura cuja autoridade respeitam - Jesus - que, apesar da gravidade da doença, Lázaro estaria apenas descansando em seu sono. O problema, porém, é que a cena não se resume a isso: ela é uma típica construção cômica, na qual um personagem diz uma palavra com um sentido A e os seus interlocutores a entendem em um sentido B, oposto a A. Dessa maneira, nós, leitores, construímos em nossa leitura o cômico, que é uma consequência desse ruído comunicativo entre as personagens da cena. De Aristófanes, passando por Plauto, Gil Vicente, Shakespeare, Ariano Suassuna ou seriados da Netflix, o ruído de comunicação que acabamos de descrever continua a ser utilizado como ferramenta do riso.

Ao dizer que Lázaro dorme, Jesus está usando a palavra "adormecer" em sentido irônico, porque há um significado oculto, incongruente em suas palavras. Embora "dormir" e "estar morto" possam ser relacionados, no sentido de uma ideia de imobilidade dos corpos nos dois momentos, ainda assim, trata-se de realidades bem diferentes. O sono não é uma morte: ele é uma das dinâmicas do próprio viver. Além de ser irônico, Jesus usa a palavra como um eufemismo, já que, no trecho, "adormecer" deve ser interpretado como "morto". Os discipulos, no entanto, leem "ao pé da letra" o verbo adormecer. É digno de nota que o narrador não confie totalmente em nós, leitores, e tenha que explicar a sua própria "sacada" literária: "É que Jesus falara da morte de Lázaro, mas eles pensaram que ele está falando do descanso do sono".

Por que Jesus fala com os discípulos dessa maneira? Eles sabem que Lázaro está doente, mas não têm ideia se o amigo morreu, ou não. Jesus se comporta assim porque ele não se dirige somente aos seus discípulos, mas a nós, leitores. 
Quando ele finalmente revela a verdade - a de que Lázaro morreu -, o texto de João enfatiza, aos nossos olhos e aos dos discípulos, a divindade de Cristo e os seus poderes sobrenaturais. O poder é, nesse caso, a onisciência. A ironia verbal não termina na comicidade do breve diálogo entre Jesus e os discípulos. Segue-se ainda o comentário de Tomé: "Vamos também nós para que morramos com ele". Como vimos, o contexto da fala de Tomé é a ansiedade do grupo pelo crescente clima de perigo que cerca Jesus. Seus ensinamentos e prodígios cada vez mais incomodam as autoridades religiosas, o que pode levar (e levará) a encarceramento e assassinatos.

Segundo Lourenço (cf. EVANGELHO SEGUNDO JOÃO, 2017, p. 374, nota de rodapé), na fala de Tomé, o pronome "ele" se refere a Jesus e não a Lázaro. Acredito, no entanto, que pode haver uma ambiguidade de sentido no pronome, que se refere, então, tanto a Lázaro quanto a Jesus. Imaginemos que Tomé não tenha coragem de dizer essa fala na frente de Jesus, o que seria plausivel, visto que o narrador faz questão de informar que Tomé se dirige aos "condiscípulos": o tom com o qual a personagem diz a frase não é esclarecido pelo narrador, porém uma paráfrase interpretativa do que Tomé fala poderia ser algo como um "Ok, ok, lá vamos nós morrer com ele...", dito em voz baixa, inclusive. A ironia, portanto, está em sua fala também, já que a fatalidade da frase implica uma tensão entre o viver e o morrer. João 11 deixa bem clara a preocupação dos discípulos com a sua própria segurança. Não há neles a resignação da missão suicida, portanto Tomé, embora obedeça a Cristo, não abre mão de ironizar a decisão do seu Mestre.

Se identificamos ironias verbais, encontramos, por outro lado, ironias situacionais? Sem dúvidas. João 11 é por si só uma grande ironia situacional. A ironia reside no fato de que o maior milagre de Jesus, o da ressurreição dos mortos, é o gatilho narrativo que levará à sua prisão e posterior crucificação. A celebração da vida tem o significado oculto da motivação para a morte. Aquele que traz a vida para os humanos - Jesus, o Deus encarnado - será, posteriormente, assassinado pela humanidade. A sua morte, porém, vai engendrar a vida, pois Jesus ressuscitará dos mortos. E a sua ressurreição - segundo a teologia cristã - é o caminho para que nós, pecadores, superemos a morte e tenhamos vida eterna. É uma construção discursiva poderosa, a da circularidade entre morte e vida. Não por acaso, alimenta imaginação e fé há milênios.

João 11, como uma longa ironia situacional, é formado por cenas individuais situacionais. Queremos destacar duas das principais. Primeiro, as cenas com as reações das pessoas que cercam Jesus. Elas nunca o entendem totalmente. Isso não é só verdade para os discípulos, como também para Marta e Maria. Nesse caso, queremos destacar outro conjunto de personagens, ou, melhor dizendo, uma personagem "coletiva", composta pela multidão anônima que tudo observa. Vejamos: "Os judeus diziam: 'Como ele o amava!'. Alguns deles disseram: 'Não podia este, que abriu os olhos do cego, ter feito com que ele não morresse" (João 11:36-37, grifo nosso).

Se "adormecer" era a palavra-chave da ironia verbal dos diálogos cômicos da cena analisada anteriormente, "cegueira" é a ideia-chave que compõe não só esse trecho, mas o comportamento de todos os personagens de João 11, à exceção de Jesus e Lázaro. A cegueira é aqui um comentário irônico a respeito da dificuldade das personagens em entender não só o ministério de Jesus, mas também a sua real identidade. Estar cego não é somente uma deficiência visual, é uma 
maneira de metaforizar a não compreensão. Uma das camadas de ironia da citação é o fato de que, ao comentarem do cego curado, as personagens não conseguirem entender que eles próprios, na visão do narrador, estão igualmente cegos, embora a cegueira neles seja espiritual. Lembremos, como foi apontado nas páginas anteriores, que a "cegueira" dos que o cercam é um dos motivos da constante irritação de Jesus ao longo do episódio.

Após o infame comentário da cegueira, Lázaro ressuscita. Jesus aproxima-se da gruta onde o corpo do amigo foi sepultado e ordena: “Lázaro, sai cá para fora!'. O morto saiu com os pés e as mãos ligados de panos e com o rosto ligado com um sudário. Diz-lhes Jesus: 'Desligai-o e deixai-o andar"' (João 11.43-44). O narrador não nos diz de modo direto, porém, o que um morto ressuscitado faz assim que volta à vida? Abre os olhos. A frase "Não podia este, que abriu os olhos do cego, ter feito com que ele não morresse" é retomada pela cena da ressurreição de Lázaro.

Jesus cumpre o desejo da multidão - ele "abriu os olhos do cego". A expressão "abrir os olhos", usada pelos observadores de maneira metafórica no sentido de uma cura orgânica, é retomada, de modo implícito, na narrativa como algo literal: o morto abriu os olhos, porque ele voltou à vida. Ainda nessa cena, além da referência à ceia, destacada antes por nós, identificamos uma referência ao parto. A gruta da qual emerge o adulto ressuscitado não deixa de ser uma paródia do bebê que é retirado do corpo de sua mãe, o que por sua vez ecoa todo o debate, conduzido pelos Evangelhos, do "nascer de novo" vinculado ao ministério de Jesus Cristo na Terra. Nessas observações, há também, e com isso encerramos nossa análise, mecanismos da ironia intratextual e intertextual. Conforme apontado, as ironias verbais e situacionais retiram parte de sua força literária devido ao fato de que, a todo momento, estão referenciados outros textos bíblicos e episódios anteriores e posteriores a João 11 .

\section{Conclusão}

Por fim, é possivel atestar a existência de realismo e ironia em João 11 ? Nossa resposta é sim. Os dois recursos são uma das bases da riqueza literária não somente do episódio, como do próprio Evangelho de João. Utilizar uma escrita realista e de profunda ironia contribui não só para a construção de uma verossimilhança histórica, mas também o realismo nos aproxima da dimensão humana de Jesus. A ironia, por outro lado, é um rico recurso textual que serve como mecanismo de sedução literária e como uma ferramenta discursiva que acentua a mensagem teológica do Evangelho. Pelas "tintas" da ironia, o Evangelho de João quer nos ensinar as verdades sobre quem Jesus foi e qual teria sido sua missão na Terra.

\section{LÁZARO: REALISM AND IRONY IN JOHN 11:1-55}

Abstract: Our article proposes a literary analysis of an important episode in the Gospel of John: that of the resurrection of Lazarus, narrated exclusively in the Gospel quoted in chapter 11, verses from 1-55. Our reading will try to stick to some elements: 1 . standard scenes and parallelisms; 2 . the construction of moments of narrative suspense and tension; 3 . the characterization of the characters, with an emphasis on the construction of the figure of Jesus in the episode; 
4. the handling of codes and procedures linked to the notions of "realism" and "irony". Our analysis will be based on the translation of the Gospel of John made by Frederico Lourenço (2017). As a theoretical basis, our research is based on A arte da narrativa biblica (ALTER, 2007), New testament history and literature (MARTIN, 2012), Mimesis (AUERBACH, 2021), Abaixo as verdades sagradas (BLOOM, 2012), and Ironia e suas refrações (ALAVARCE, 2009).

Keywords: Gospel of John. Irony. Realism. Bible. Literary criticism.

\section{REFERÊNCIAS}

ALAVARCE, C. da S. A ironia e suas refrações: um estudo sobre a dissonância na paródia e no riso. São Paulo: Cultura Acadêmica, 2009.

ALTER, R. A arte da narrativa bíblica. São Paulo: Cia das Letras, 2007.

AUERBACH, E. Mimesis: a representação da realidade na literatura ocidental. São Paulo: Perspectiva, 2021.

BLOOM, H. Abaixo as verdades sagradas: poesia e crença desde a Bíblia até nossos dias. São Paulo: Cia das Letras, 2012.

ECO, U. Sobre literatura. Rio de Janeiro: BestBolso, 2011.

EVANGELHO SEGUNDO JOÃO. In: Bíblia. Novo Testamento. Os quatro Evangelhos. Tradução Frederico Lourenço. São Paulo: Cia das Letras, 2017. p. 313-412. KERMODE, F. João. In: ALTER, R.; KERMODE, F. (org.). Guia literário da Bíblia. São Paulo: Editora Unesp, 1997. p. 473-499.

MARTIN, D. B. New testament: history \& literature. New Haven: Yale University Press, 2012. 